\title{
Sistem Informasi Perpustakaan Berbasis Web Application
}

\author{
Yudie Irawan $^{\mathrm{a}}$, Mustafid $^{\mathrm{b}}$, Aris Sugiharto $^{\mathrm{b}}$ \\ aUniversitas Muria Kudus, Kudus \\ ${ }^{b}$ Magister Sistem Informasi, Universitas Diponegoro Semarang
}

\begin{abstract}
Digital library system contributes the development of digital resource digital resource that can be accessed via the Internet. Library management system contributed to the development of automation membership data processing, circulation and cataloging. In this thesis is to develop a new concept of digital library systems and library management system by integrating these two systems architecture. Integration architecture implemented by inserting component library management system into the digital library system architecture. Web application technology required for these components in order to be integrated with the digital library system components. The new system has the advantage of this development application utilization of borrowing, membership and kataloging to a sharable over the internet, so applications that can be used together. Information can be delivered between the library catalog, without leaving the digital library function in the utilization of shared digital resources derived from uploading by each librarian.
\end{abstract}

Keywords : Digital library system; Library management system; Web application

\section{Pendahuluan}

Di awal pengembangan digital library, para peneliti lebih memberikan perhatian pada layanan sistem dan peningkatan jumlah digital resource yang dihasilkan, seperti halnya yang disampaikan oleh Cleveland (1998), bahwa digital library - digital library yang ada akhirnya menjadi kumpulan sumber daya yang berbeda dan juga sistem yang berbeda, hal ini disebabkan karena sistem sistem itu dikembangkan untuk melayani komunitas tertentu dan kelompok - kelompok user yang ada. Pada perkembangan selanjutnya dikenal dua istilah dalam komputerisasi sistem perpustakaan, yaitu digital library system dan library management system. Pada masa sekarang kedua sistem ini lebih bersifat open source, dimana user diperbolehkan menggunakan dan mengembangkan sesuai dengan kebutuhan dan kemampuannya. Walaupun kedua sistem memiliki persamaan dalam pengelolaan data perpustakaan namun juga memiliki perbedaan yaitu pada digital library system lebih dikembangkan untuk mengelola digital resource dan cara mengaksesnya, sedangkan library management system digunakan untuk mengelola sirkulasi, keanggotaan, kataloging dan online public access catalog.

Pada sisi lain kebutuhan mencari referensi buku (nondigital resource) dengan memanfaatkan otomatisasi perpustakaan semakin meningkat karena informasi lebih cepat didapat dengan bantuan otomatisasi. Selain itu juga disadari bahwa pemanfaatan non-digital resource tetap tidak dapat digantikan oleh digital resource. Sehingga pemanfaatan aplikasi otomatisasi pada pencarian nondigital resource khususnya buku akan tetap berlangsung dan hingga sekarang. Keunggulan digital library system adalah memberikan kontribusi akses download digital

Email: yudie_i@yahoo.com resource dari manapun melalui internet. Namun digital library system tidak menyediakan informasi tentang nondigital resource. Sebaliknya, pada library management system memberikan kontribusi pada pengelolaan operasional perpustakaan yang secara otomatis menyediakan informasi non-digital resource. Namun pada library management system tidak menyediakan digital resource dan pemanfaatannya. Oleh karena itu sistem perpustakaan perlu dikembangkan agar mampu memenuhi kebutuhan pemanfaatan digital resource dan non-digital resource dengan lebih optimal.

Penelitian ini bertujuan membuat rancangan pengembangan sistem informasi perpustakaan dengan mengintegrasikan arsitektur antara digital library system dan library management system agar dapat mengadopsi masing - masing keunggulan yang dimiliki oleh kedua sistem tersebut.

\section{Kerangka Teori}

Arsitektur Delos mengadopsi pendekatan berlapis, dan mengatur komponen konstituen menjadi tiga tingkatan (Candella, 2006) :

a. Application Frame, yaitu set perpustakaan dan subsistem yang mendukung pengoperasian komponen sistem Digital Library (DL) lainnya;

b. Enabling Component, yang menyediakan

c. fungsionalitas yang dibutuhkan untuk mendukung kerjasama antar komponen mengimplementasikan aplikasi DL,

d. DL Application Component, yang menyediakan fungsionalitas DL khusus untuk pengguna akhir.

Menurut Heery (2001) Use case diagram digital library terdiri dari 7 (tujuh) use case yaitu :

1. discover resource, fungsi menemukan resource atau digital collection, fungsi ini memiliki dua fungsi turunan yaitu search(simple) maupun search(complex) 
2. search(simple), fungsi untuk mencari digital collection dengan memasukkan filter sederhana.

3. search(complex), fungsi untuk mencari digital collection dengan memasukkan filter yang lebih detail.

4. choose interface language, fungsi ini disediakan untuk mengganti bahasa pengantar sesuai bahasa user. Fungsi ini minimal menyediakan bahasa setempat dan bahasa internasional.

5. cross browse by subject, fungsi yang digunakan untuk mencari lintas web menggunakan subjek

6. cross browse by metadata fungsi yang digunakan untuk mencari lintas web menggunakan metadata.

7. data information landscape fungsi yang menyediakan peta informasi

Menurut Rosasco dan Bakke (2005), sistem Koha dikembangkan berdasarkan pada kebutuhan komunitas perpustakaan yang berkolaborasi yang sedang berkembang untuk mencapai tujuannya secara teknologi. Koha terus mengembangkan fasilitasnya untuk memperluas dan memenuhi kebutuhan dasar penggunanya. Perpustakaan umum pertama di Amerika Utara mendanai dukungan penggunaan MARC dan mulai menggunakan Koha pada tahun 2003. Koha sekarang digunakan hampir di seluruh dunia, terutama di perpustakaan kecil. Arsitektur Koha terdiri dari beberapa modul atau function yang dikirim atau diakses ke web antara lain Circulation, Acquisition/Budget, Patrons, Non MARC, MARC, Fines, Admin, Export, Import. Modul - modul tersebut mengakses database dengan DB Wrapper. Daemon adalah sistem client server yang digunakan untuk mendukung fungsi - fungsi agar dapat menjalankan aplikasi. Arsitektur Koha dapat dilihat pada Gambar 1.
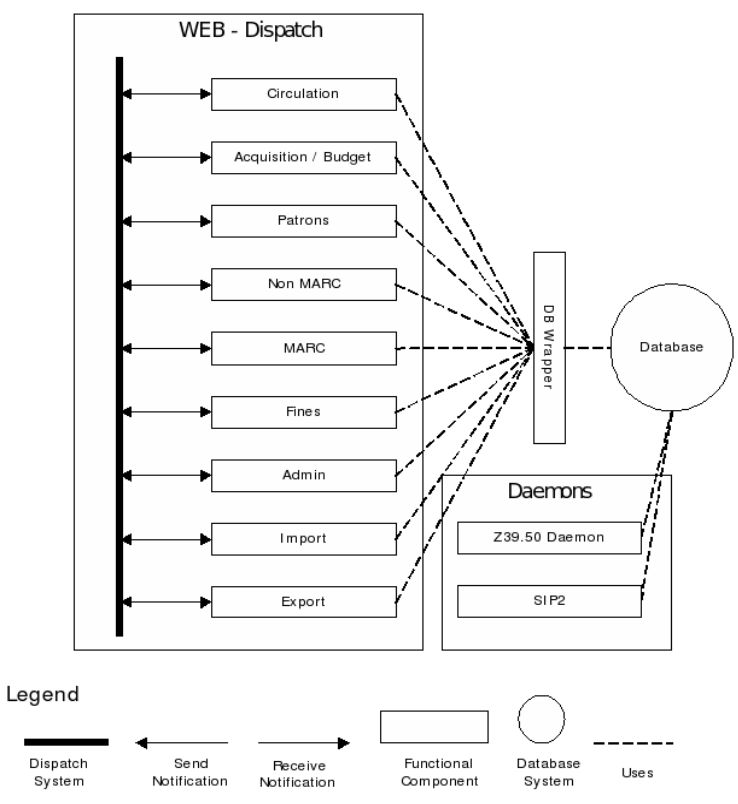

Gambar 1. Arsitektur KOHA

(Sumber : Rosasco dan Bakke, 2005)

Pada use case diagram library information system, sesuai yang dibahas oleh Rosasco dan Bakke (2005), seperti yang terlihat pada Gambar 2, terdapat tiga use case diagram yang didalamnya terdiri atas beberapa use case, yaitu : patron use case diagram, circulation use case diagram dan cataloging use case diagram.
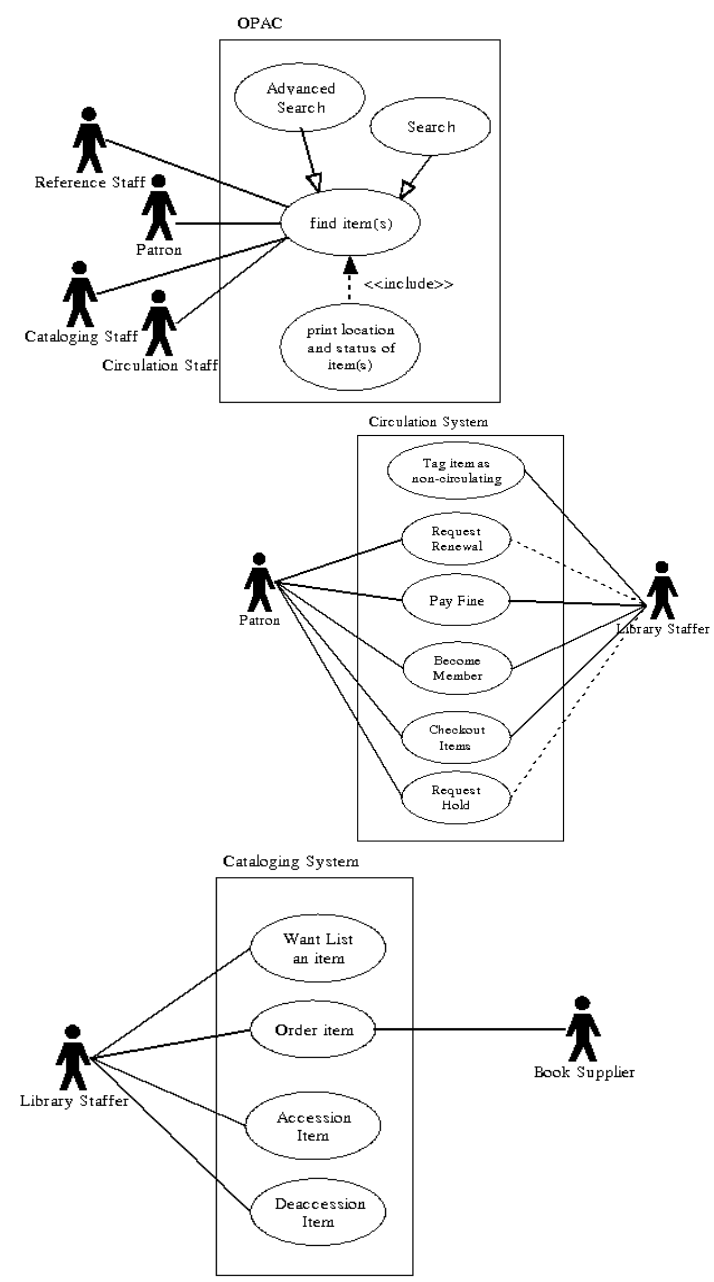

Gambar 2. Use case diagram library information system Sumber : Rosasco dan Bakke, 2005

Pada Patron use case diagram atau OPAC (Online Public Access Catalog) terdapat 4 (empat) use case yaitu ;

1. Find items, yaitu fungsi untuk menemukan informasi items (katalo/buku)

2. Advance search, fungsi yang menyediakan pencarian lanjut/mahir, yaitu pencarian dengan banyak filter.

3. Search, fungsi yang menyediakan fasilitas pencarian item secara sederhana, yaitu dengan satu filter.

4. Print location and status items, fungsi yang menyediakan fasilitas cetak lokasi dan status buku.

Pada Circulation use case diagram terdapat 6 (enam) use case yaitu;

1. Tag item as non-circulatin: fungsi yang memberikan fasilitas untuk buku referensi saja atau buku yang boleh dipinjam.

2. Request Renewal; fungsi yang menyediakan fasilitas mengusulkan buku baru.

3. Pay fin; fungsi yang menyediakan fasilitas pembayaran denda 
4. Become member; fungsi untuk mencata pendaftaran anggota baru

5. Checkout item; fungsi untuk memeriksa status buku

6. Request hold; fungsi untuk mencatat pemesanan buku yang akan dipinjam

Pada Cataloging system use case diagram terdapat 4(use case), yaitu ;

1. Want List item; fungsi yang menyampaikan daftar permintaan pinjam buku

2. Order item; fungsi yang memberikan fasilitas mengorder buku ke supplier

3. Accesion item; fungsi untuk memberikan hak akses pada buku

4. Deaccesion item; fungsi untuk menolak hak akses pada buku.

\section{Metodologi}

Pengembangan sistem informasi perpustakaan dalam penelitian ini menggunakan integrasi arsitektur digital library system dengan library management system agar dapat mengadopsi masing-masing keunggulan yang dimiliki oleh kedua sistem.

Sebagai pijakan pengembangan, peneliti menganalisa arsitektur Delos DLMS sebagai digital library system (dls) dan Koha ILS sebagai library management system (lms). Integrasi dilakukan dengan memasukkan komponen library information system ke dalam arsitektur digital library system. Sub sistem atau komponen - komponen tersebut dibangun dengan web programming application agar dapat diakses sejajar bersama komponen lain melalui internet. Arsitektur Delos DLMS dapat dilihat pada Gambar 3 dan use case digital library system disampaikan pada Gambar 4.

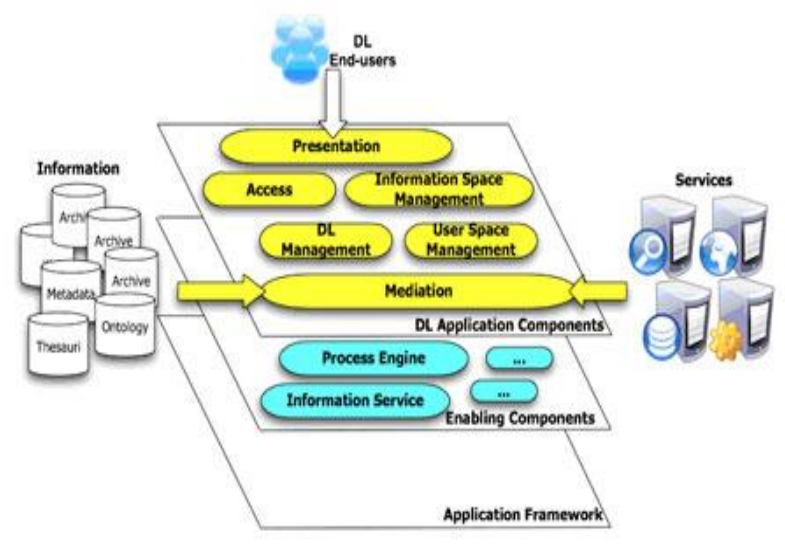

Gambar 3. The digital library system reference archit.ecture (Sumber: Candella, 2006)

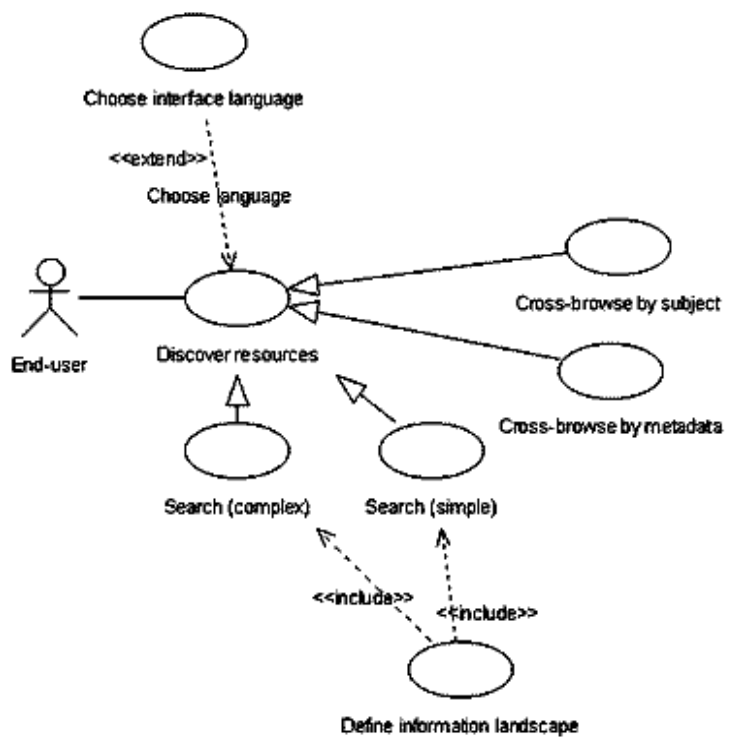

Gambar 4. Use case diagram digital library system (Sumber : Heery, 2001)

\section{Hasil dan Pembahasan}

Berdasarkan pada dua arsitektur dan use case diagram, integrasi dilakukan dengan memasukkan komponen library information system ke dalam arsitektur digital library system. Komponen tersebut dibangun dalam web platform agar dapat diakses sejajar bersama komponen lain melalui internet. Dengan metode ini maka komponen tersebut dapat digunakan bersama melalui web browser (sharable) secara online.

Arsitektur digital library system menggunakan pendekatan berlapis. Pada lapis paling atas disebut $D L$ Application Components, yaitu lapisan yang menyediakan fungsionalitas DL khusus bagi end user atau disebut sebagai client side. Pada layer tersebut komponen library management system yaitu ;circuliation, fines, import/download, export/upload, dan admin space management disisipkan. Dengan meletakkan komponen tersebut pada lapis atas maka memungkinkan user/pustakawan mengaksesnya, sesuai fungsinya, termasuk komponen admin space management.

Pada lapis tengah terdapat Enabling Component yang disisipi DBWrapper, yaitu aplikasi Database Management System yang mengelola alur kerja sama dengan Process Engine. Pada lapis terbawah yang disebut Application Framewor, atau server side terdapat penambahan komponen Web Server, tempat dimana web application diinstall dan dijalankan. Pada lapis ini hanya SysAdmin yang memiliki hak akses mengelolanya. Use case diagram dan arsitektur gabungan disampaikan pada Gambar 5 dan Gambar 6.

Dengan integrasi sistem ini maka anggota perpustakaan dapat menemukan digital resource dan nondigital resource(katalog dan buku) sekaligus dalam satu aplikasi. 
Fasilitas download dan membaca tetap melekat pada digital resource, sistem juga menyediakan fasilitas operasional untuk katalog atau buku. Komponen circulation yang berjalan secara online mampu diakses oleh pustakawan manapun untuk membantu operasional peminjaman dan pengembalian. Walaupun database diletakkan dalam satu server atau terpusat, namun data yang diakses oleh masing - masing pustakawan berbeda menurut kepemilikannya.

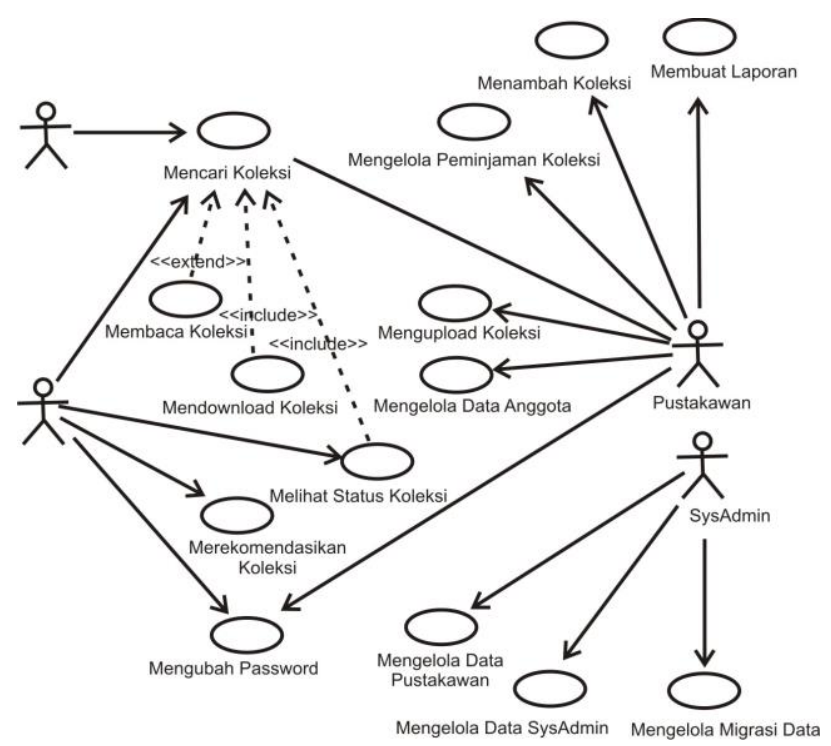

Gambar 5. Use case diagram integrasi digital library system dan library management system

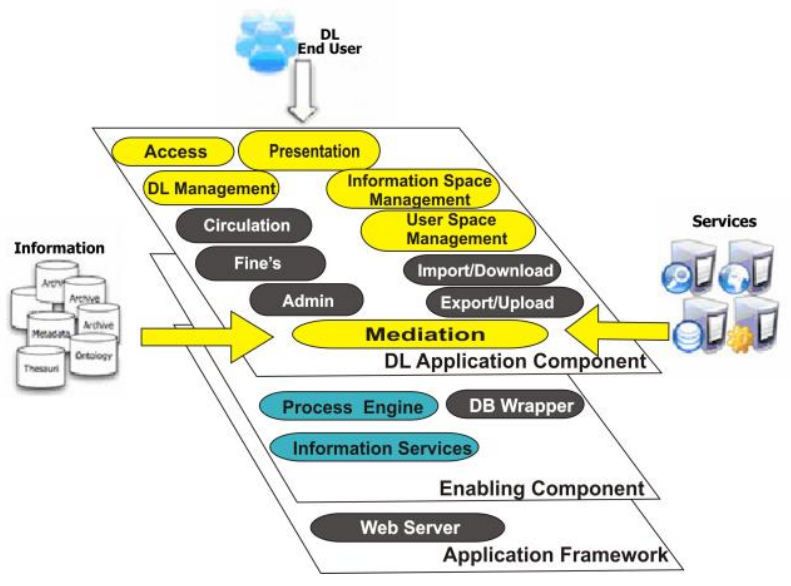

Gambar 6. Arsitektur hasil integrasi digital library system dan library management system

\section{Kesimpulan}

Pengembangan software dewasa ini banyak yang mengarah pada web platform, karena keunggulannya yang multiplatform dan dapat berjalan pada internet secara luas, tidak terkecuali pada pengembangan aplikasi dan otomatisasi perpustakaan. Aplikasi tersebut dikenal dengan library management system dan digital library system. Fungsi library management system digunakan untuk mengolah data katalog, peminjaman, denda dan administrasi perpustakaan lainnya. Fungsi digital library system yaitu mengelola digital resource yang antara lain terdapat fasilitas upload dan download resource.

Pada tesis ini dikembangkan aplikasi perpustakaan dengan mengintegrasikan kedua sistem tersebut. Integrasi dilakukan dengan menyisipkan komponen pada arsitektur library management system ke dalam arsitektur digital library system. Integrasi yang dilakukan menghasilkan sistem yang mampu memberikan informasi non digital resource dan digital resource dalam satu aplikasi berbasis web. Pustakawan dapat memanfaatkan otomatisasi berbasis web untuk mengelola sirkulasi peminjaman dan pengembalian buku, pengaturan denda dan pendataan buku. Walaupun dengan konsep database terpusat , namun pustakawan hanya dapat mengakses data perpustakaanya sendiri.

\section{Daftar Pustaka}

Candela, L., 2006. A Reference Architecture for Digital Library System, Europan Digital Library-ERCHIM, News Online Edition.

Cleveland, G., 1998, Digital Library: Definitions, Issues and Challengges, Paper of International Federation of Library Associations and Institutions.

Heery, and Rachel, 2001. Renardus Project Developments and The Wider Digital Library Context, D-Lib Magazine April Edition.

Rosaso, N and Bakke, E., 2005. Koha Architectural Study, http://www.kohadocs.org/Koha architecture.html, Diakses 10 Pebruari 2010 